\section{Case Reports in Ophthalmology}

\title{
Choroidal Nevus-Associated Neovascular Membrane Demonstrated by OCT Angiography
}

\author{
Joel Hanhart Kobi Brosh Yishay Weill Yaakov Rozenman \\ Department of Ophthalmology, Shaare Zedek Medical Center, Jerusalem, Israel
}

\section{Keywords}

OCT angiography · Swept-source OCT · Choroidal nevus · Choroidal neovascular membrane

\begin{abstract}
We present a case of choroidal nevus, complicated by a choroidal neovascular membrane (CNV) that was detected by OCT angiography. Choroidal nevi are relatively common intraocular tumors. The presence of subretinal and intraretinal fluids can indicate that a CNV has occurred as a complication, warranting prompt management. However, subretinal and intraretinal fluids are also documented in nevi without CNV. OCT angiography may be of great help in determining whether those fluids are associated or not with a CNV, therefore guiding therapy.

(C) 2017 The Author(s)

Published by S. Karger AG, Basel
\end{abstract}

\section{Case Report}

Choroidal nevi are relatively common intraocular tumors, benign in nature and with little potential for visual loss or growth into melanoma [1]. B-scans of choroidal nevi obtained by standard spectral domain OCT may identify overlying retinal alterations, photoreceptor atrophy, and retinal pigment epithelial detachment, while enhanced depth imaging or sweptsource OCT enables characterization of the deeper features of those lesions.

Subretinal and intraretinal fluids can accompany choroidal nevi [2, 3]. In this situation, observation is usually required. On the other hand, choroidal neovascular membranes 
(CNVs) are known to rarely complicate nevi. It is crucial to promptly identify this potentially blinding complication, which can be treated by intraocular injection of agents inhibiting antivascular endothelial growth factor, even when it develops at the fovea, [4, 5].

We describe a man in his 60s, with a right macular pigmented nevus documented for years, who presented with right metamorphopsia. Visual acuity was $12 / 20$, and funduscopy revealed a macular melanotic nevus without hemorrhage. Swept-source OCT B-scans showed subretinal fluid over a choroidal nevus distending into the retina (Fig. 1). OCT angiography captured a well-defined CNV emanating from the nevus and bulging towards the neurosensory retina (Fig. 2).

This patient received 3 bevacizumab injections, with rapid disappearance of the subretinal fluid on B-scans, shrinkage of the neovascular network on OCT angiography (to the level of no detection of vascular signal), and improvement of his visual acuity to 16/20.

OCT angiography cannot demonstrate leakage and therefore, unlike fluorescein angiography, does not formally establish causality between the CNV and the subretinal fluid. However, in most cases, the association of CNV with a nevus accompanied by subretinal fluid should be sufficient to specifically address the neovascular complication.

Hence, OCT angiography may replace fluorescein angiography (Fig. 3) in determining whether subretinal and intraretinal fluids are related or not to CNV, a complication with major prognostic and therapeutic implications.

\section{Statement of Ethics}

A patient approval form was filled for publication of the pictures obtained in the course of regular consultations in our retina clinic.

\section{Disclosure Statement}

The authors report no conflicts of interest.

\section{References}

1 Shields CL, Pellegrini M, Ferenczy SR, Shields JA: Enhanced depth imaging optical coherence tomography of intraocular tumors: from placid to seasick to rock and rolling topography - the 2013 Francesco Orzalesi Lecture. Retina 2014;34:1495-1512.

-2 Francis JH, Pang CE, Abramson DH, Milman T, Folberg R, Mrejen S, Freund KB: Swept-source optical coherence tomography features of choroidal nevi. Am J Ophthalmol 2015;159:169-176.e161.

Shields CL, Furuta M, Mashayekhi A, Berman EL, Zahler JD, Hoberman DM, Dinh DH, Shields JA: Clinical spectrum of choroidal nevi based on age at presentation in 3,422 consecutive eyes. Ophthalmology 2008;115:546-552.e542.

4 Chiang A, Bianciotto C, Maguire JI, Park CH, Baker PS, Shields JA, Shields CL: Intravitreal bevacizumab for choroidal neovascularization associated with choroidal nevus. Retina 2012;32:60-67.

-5 Papastefanou VP, Nogueira V, Hay G, Andrews RM, Harris M, Cohen VM, Sagoo MS: Choroidal naevi complicated by choroidal neovascular membrane and outer retinal tubulation. Br J Ophthalmol 2013;97:1014-1019. 


\section{Case Reports in Ophthalmology}

\begin{tabular}{l|l}
\hline Case Rep Ophthalmol 2017;8:104-107 \\
\hline DOI: 10.1159/000458516 & $\begin{array}{l}\text { C } 2017 \text { The Author(s). Published by S. Karger AG, Basel } \\
\text { www.karger.com/cop }\end{array}$ \\
\hline
\end{tabular}

Hanhart et al.: Choroidal Nevus-Associated Neovascular Membrane Demonstrated by OCT Angiography

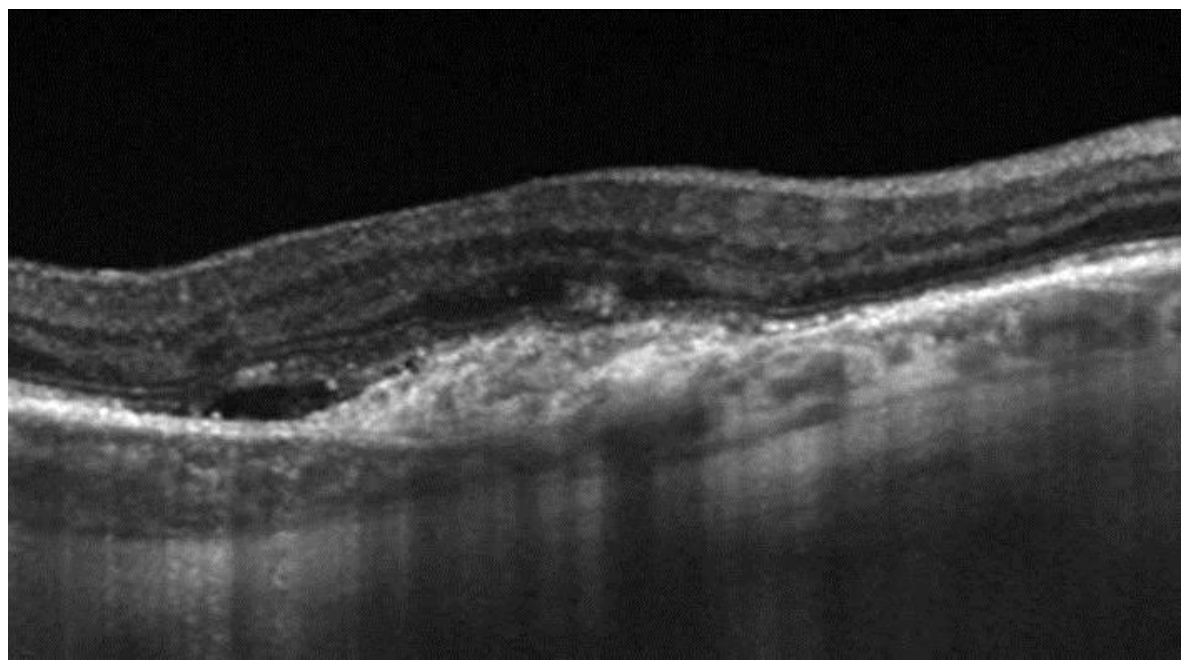

Fig. 1. Swept-source OCT B-scan. This averaged picture at the fovea reveals disorganization of the outer retinal layers above the nevus as well as subretinal fluid. The borders of the nevus can be precisely delineated.



Fig. 2. OCT angiography. Clinical examination and B-scan OCT cannot rule out the presence of a CNV. OCT angiography demonstrates a vascular lesion characterized by branching capillaries anastomosing into larger vessels and surrounded by a hypointense halo. 
Case Reports in
Ophthalmology

Case Rep Ophthalmol 2017;8:104-107

DOI: $10.1159 / 000458516$

(C) 2017 The Author(s). Published by S. Karger AG, Basel

Hanhart et al.: Choroidal Nevus-Associated Neovascular Membrane Demonstrated by OCT Angiography

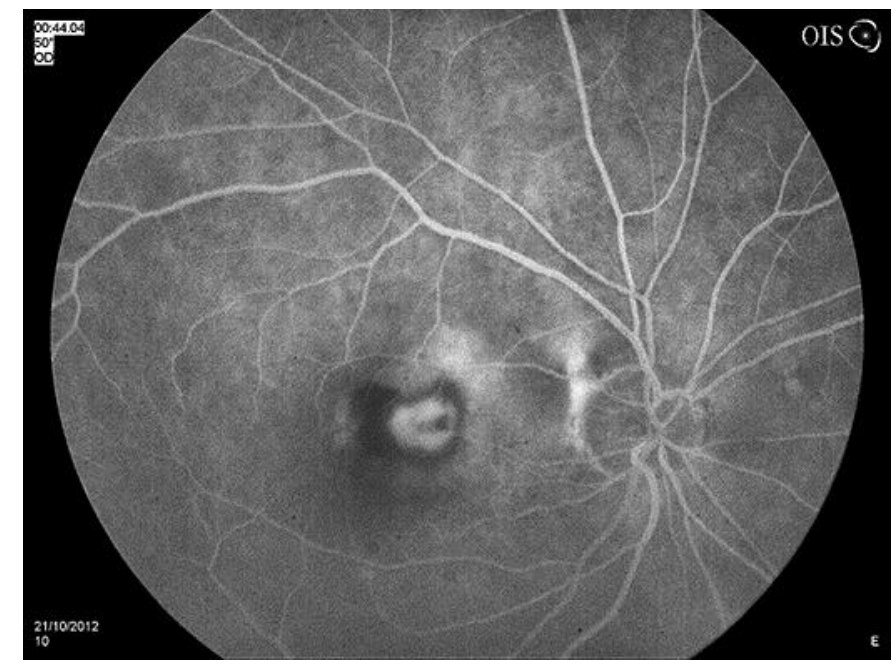

Fig. 3. Fluorescein angiography reveals a classic CNV within the nevus. 